.

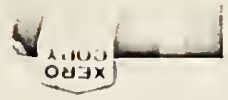

and

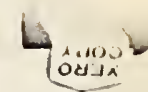

NBS Report ot 9046 supplement

SUPPLEMENT

TO

POL II

NATIONAL BUREAU OF STANDARDS REPORT NO. 9046

by

L. L. WoMAN 


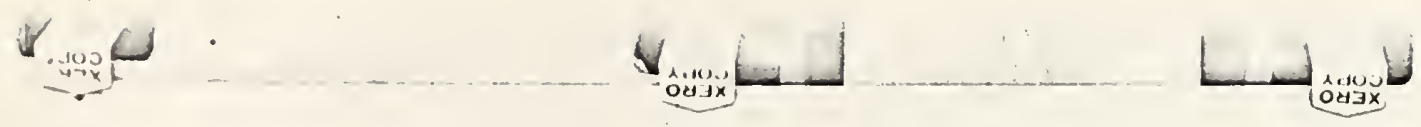

PART I.

\section{SANTIAGO SEMINAR}

Arrival in Santiago a few days prior to the official opening of the seminar was quite intentional inasmuch as I had been requested to sit down with the Seminar Director, AnibalcGomez, and $\mathrm{Sr}$. Monroy of the Mexican delegation in order to try to formulate some guidelines for the operation of the seminar.

\subsection{OPERATION OF DIRECCION GENERAL DE NORMAS}

This standards organization, DGN, a branch of the Mexican government in the Department of Commerce and Industry is operating with a "new look" under the director and assistants appointed following last year's elections. In essence, DGN will not write standards as heretofor -- and so objectional to industry -. but has now passed this work over to the trade associations (Camaras) of each industry to cooperate with their customers to produce what they consider to be satisfactory proposals. The camaras will turn these completed documents over to DGN for. "discussion" for a designated time period.

At the termination of this period, the particular camara will review any comments with $D G N$, waking any necessary changes or revisions, following which DGN will officially adopt the proposals as standard:

To implement this procedure, the several camarss have appointed standards committees to forumlate desired proposals.

In the instance of the steel committee of the Mexican Iron $E_{5}$ Steel Institute which has seven subcommittees, the one on pipe and tubes had performed a monumental task in reviewing in detail the items to be considered at the Santiago seminar. They had not only prepared suitable substitutes, but had even translated a number of ASTM standards intor Spanish, arranged the material in the desired format, and had them ready for consideration at the seminar. They were most acceptable.

From the report supplement to my Mexican visit of July, 1964, the dilemna of Mexican industry with the government operated standards organization was made clear. From the foregoing it becomes evident that the voice of industry was "heard" -- and standards-writing passed over to industry to every extent legally possible.

Unfortunately, the law creating DGN even stipulates the format of DGN standards. I am advised that it is a very bad format - but nothing can be done about it; that is, unless their congress will change the law. 
. 
It may be best to repeat here the comment made in the reports of the earlier tube seminars; this being to the effect that the Mexican steel industry is patterned after our own, thus the Mexicans are U.S. minded in steel practice and steel standards.

Being truly Latin Americans, and firmly determined to protect their interests, they have actually been waging our cause, thus permitting U.S. representation to be less forward and thus avoid any possible accusation of big-brother-dictating. 
.

-

- 


\subsection{INDITECNOR OPERATION}

The Instituto Nacional de Investigaciones Tecnologicas $y$ Normalizacion (INDITECNOR) is the standards organization of Chile, and is a branch of the government operated under the University. Its director is the venerable and venerated Dr. Carlos Hoerning, who, it among many honors, is Dean Emeritus, of the Engineering University.

This organization has been feeble for more than a few years and, as previous reports have noted, is intended for a complete rehabilitation. Dr. Hoerning, having more or less recovered from lengthy illnesses, is striving valiantly to revive INDITECNOR. However, as he advised me this trip (and as I reported two years ago, and he did not know), he is aware of the impending action -- also that it will undoubtedly involve his replacement.

Dr. Hoerning again requested assistance for INDITECNOR, repeating his last-years reference to our ICONTEC assistance.

I discussed such possibilities with Dr. "Cap" Green, AID Director, once more, and there are possibilities. However, as I had advised Dr. Hoerning both last year and this year, this must be done "via" channels" inasmuch as his organization is a branch of the GOC, not an independent private organization such as ICONTEC in Colombia.

Dr. Green is again willing to discuss this matter with Dr. Hoerning on the latter's request.

This year, Dr. Hoerning is citing the need of typewriters, duplicating equipment, etc., and is hesitant to discuss technical assistance because he claims that if he accepts such from the U.S. he must also welcome the British, French, Germans, etc. He would not do this without the approval of his $B / D$-- but $I$ am still unaware that he bas brought this to the attention of the Board.

Further in this connection, Dr. Hoerning says that many people criticize him as leaning toward DIN standards because of his ancestry.

There are but very few young men active in INDITECNOR affairs, according to Dr. Hoerning. This is quite apparent to those of us familiar with the organization and, most unfortunately, for good reasons -- including lack of industry support.

The latter is quite understandable because approved standards become law in Chile, and have harassed industry. 
The reorganization of INDITECNOR is directly in the hands of COREO, the development cooperation in Chile. The responsible man is Dr. Raul Saez, Vice President, who, in turn, has delegated some of the planning to Ing. Salvatore Lluch, Managing Director of the Chilean Iron and Steel Institute.

At the time of this visit, Dr. Saez was completely incommunicado, except for copper discussions, due to the unrest in that industry and the promotion of the government plans for the copper industry through the congressional approval.

Due to impending changes in management of an important trade organization, probably the better of the two candidates for successor to Dr. Hoerning is no longer available.

It is most likely that our advice and technical assistance will be requested in this reorganization of INDITECNOR.

\subsection{ASTM ACTIVITIES}

There is quite a group, some 18 members, of ASTM in Chile, and there is a rapidly growing repect for ASTM.

Some of the Santiago members discussed with me the possibility of forming an ASTM District Council in Chile. While this is an excellent idea, and should be put into effect as soon as possible, I found that, after disscussion with several of the Santiago members, there was a general agreement that such a move could very easily be misinterpreted as a "pressure move" by ASTM at this time of indecision as to the future of INDITECNOR.

At a dinner for ASTM members, it was my pleasure to make some new acquaintances, and also to have a few minutes to chat with Prof. Enrique D'Etigny L., Dean of the Faculty, University of Chile, which also automatically places him as the Vice-President of the $B / D$ of INDITECNOR.

At the request of Ing. Hans Eggers, Uruguay, I was happy to endorse his ASTM membership application, as did Pineda. 


\subsection{SEMINAR DELEGATIONS}

In privately discussing the approved delegations in the days before the seminar began, several items of interest came to light:

1. Argentina would have a new head-of-delegation, and had been instructed to be more cooperative.

2. Mexico would have new men; but they were technically wellqualified and had been very active in their steel $=$ standards committee.

3. Brazil would have but two delegates, the financial difficulties of the Mannesmann organization preventing the attendance of Kuritescu.

4. Chile and Uruguay would have the "old timess" back.

5. The U.S. Would have a second representative, Pineda -- a native Santiagoan, retired Lieut. of the Chilean Navy, now an Assistant Tech. Secy. of ASTM.

6. Ing. Fernando Aquierre Tupper, Managing Director of ILAFA was in Europe on business, so Ing. Anibal Gomez was acting as the senior officer of that organization.

\subsection{IRAM DIFFICULTIES}

It was rumored early, and I later confirmed, that IRAM was having financial difficulties -- one important reason being that the major funding that it had been receiving from the industrial research institute INTI (government supported) had been withdrawn.

\subsection{ILAFA CHANGES}

While no public announcement had been made, it was no secret that Ing. Fernando Aguirre $T$. would relinquish his ILAFA position early in ' 66 to become head of Chile's only steel mill, CAP.

Ing. Anibal Gomez would naturally take over the management of ILAFA. 


\subsection{SEMINAR SESSIONS}

Although the course of the seminar was smoother than in previous years, there were a few rought spots which were due to (a) lack of background in steel technology and standardization, or (b) unwillingness or inability to "understand" -- or both.

On three separate occasions the inter-delegation differences among the Argentines were so intense that they had to excuse themselves for a skull-session in order to arrive at a decision.

The seamless group lost, by my actual count, $21 / 2$ days due to the injection of a company merchandizing problem on one tube product by the junior Argentine delegate -- and the head-of-delegation did not know that this was NOT a problem for this seminar, nor any other standards group.

They both learned -- the hard way. In fact, another L.R. delegate pointedly asked them why they didn't go to the U.S. and work with ASTM Committees, as did he, and learn how to do things right.

For several days we enjoyed the presence of Ing. Rodolfo Meyer B., General Supt. of Aceros Alfa Monterrey, S.A., Mexico, who was visiting several L.A. countries on business.

We had several interesting chats during his brief stay, but before he left he informed me that be would go crazy trying to get standards written under our operating conditions -- he'd prefer to stay in the mill.

On my inquiry, he gladly gave permission for Ing. Romero to stay over as long as necessary to wind up the seminar work.

Another significant factor which saved much general argument, thus preventing loss of time, was in the repeated instances where there were honest differences of opinion between "old-timers" wherein it became quite usual for them to argue it out in private. Knowing and respecting each other through previous seminars fosters such actions and saves much time -- and tempers.

In the 1963 seminar, the Argentine head-of-delegation was insistent on the inclusion of preferred number sizes, statistical sampling, complete metricism, etc., thus giving rise to many of the compromises which were made. 
During the 1964 meeting, this representative received a number of set-backs in this effort to impose the theoretical on the practical.

One can note that these were ignored at the 1965 meeting.

In his report on the asbestos-cement pipe seminar (which in several previous meetings had switched from ISO to ASTM specifications) recently held in Buenos Aires, Mr. K. H. Kollar, BDSA, our U.S. delegate notes unfavorably the efforts of IRAM to supercede the prectical with untried theoretical methods. So here we have the same organization trying to impose their concepts in two quite different disciplines.

This could give rise to more than a bit of conjecture as to (a) whether or not this is one source of IRAM's difficulties, and (b) if this contagium is affecting the IRAM-associated COPANT operations.

\subsection{COPANT OPERATIONS}

For the third successive year steel tube seminars have recommended changes in COPANT operations -- without result.

The most important of these is the unsuitability of the COPANT format for steel tube standards; another is the insistence that the Basis of Purchase is "ordering information" and must be in an appendix.

It is most unfortunate that such regulations, established by dictum at the inception of COPANT, should prevail in the presence of repeated objections by the working committees -- the people who really know and who should be doing the deciding! 


\section{PART II}

\section{ICONTEC SEMINARS}

During my brief stop-over in Bogota to make plans for the 1966 seminar work, there come to light several factors which had an appreciable bearing on these plans.

Last year, our experts were expected to devote approximately half-time to presentations and discussions with business leaders of the broader aspects -- technical, economic, and legal -- in their several disciplines.

These sossions were not too successful, primarily due to the fact that most of our people have neither the knowledge nor the experience in the non-technical aspects of standards.

As the consequence of this, together with the bold fact that ICONTEC must do missionary work with "top business" of Colombia to get them over to the U.S. concept of "voluntary standardization" -and participation in and support of this effort, the proposal that I spearhead such a move in the principal industrial centers of Colombia was placed before me. This I could scarcely refuse, so such is the plan.

Another factor which came to light was that while some of our experts seemed to be very competent, technically, they were too cold and aloof, thus failing to get their story across to these people.

With factors such as these in mind, it is incumbent that we pay greater attention to the personalities of our epresentatives -- as well as to their much more careful briefing on cooperation with our good neighbors to the South.

ICONTEC was in no small measure responsible for the lack of complete success of some of the seminars; this being primarily due to poor attendance at comittee and even the cancellation of a few meetings.

This subject was thoroughly discussed with Messrs. Fitch and Henao to the extent, that such will not occur in this next series of seminars. Also, the new committees will be fully activated immediately in preparation for their seminars. 


\section{WEIGHTS AND MEASURES PROGRAM}

Having made all the arrangements for having the WGM laboratory at the University, it was with a great deal of pleasure that I could now visit this excellent establishment and discuss its functioning with Drs. Franco and Silva.

This meeting rapidly came to complete agreement on both sets of plans; that for the training mission for Prof. Silva, and for the training program in July - August udner Mr. Stabler.

From all indications, it would seem that quite a few L.A. countries will be sending trainess to this session. 
$\because$ 